\title{
INCISIONAL NEGATIVE-PRESSURE WOUND THERAPY IN REVISION TOTAL HIP ARTHROPLASTY DUE TO INFECTION
}

\section{TERAPIA DE PRESSÃO NEGATIVA INCISIONAL NA REVISÃO DE ARTROPLASTIA TOTAL DO QUADRIL POR INFECÇÃO}

\author{
Helder de Souza Miyahara ${ }^{1}$, Felipe Ribeiro Serzedello ${ }^{1}$, Leandro Ejnisman ${ }^{1}$, Ana Lúcia Lei Munhoz lima ${ }^{2}$, \\ José Ricardo Negreiros Vicente ${ }^{1}$, Camilo Partezani Helito 3,4 \\ 1. Universidade de São Paulo, Faculdade de Medicina, Instituto de Ortopedia e Traumatologia, Hospital das Clínicas HCFMUSP, Hip Group, São Paulo, SP, Brazil. \\ 2. Universidade de São Paulo, Faculdade de Medicina, Instituto de Ortopedia e Traumatologia, Hospital das Clínicas HCFMUSP, Hospital Infection Committee, São Paulo, SP, Brazil. \\ 3. Universidade de São Paulo, Faculdade de Medicina, Instituto de Ortopedia e Traumatologia, Hospital das Clínicas HCFMUSP, Knee Group, São Paulo, SP, Brazil. \\ 4. Hospital Sírio Libanês, São Paulo, Brazil.
}

\section{ABSTRACT}

Objective: To present our institution's experience with negative-pressure wound therapy (NPWT) as an adjuvant in wound healing of patients who have undergone revision total hip arthroplasty (THA) due to septic loosening in the presence of active fistula. Methods: We prospectively assessed patients presenting with THA infection, associated with the presence of fistula, treated with a PICO ${ }^{\circledR}$ device for NPWT, in combination with the standard treatment for prosthesis infection in our institution. Resolution of the infectious process and healing of the surgical wound without complications were considered an initial favorable outcome. Results: We assessed 10 patients who used $\mathrm{PICO}^{\circledR}$ in our department. No complications were identified in association with the use of the NPWT device. The mean follow-up of the patients after use of the device was 12.7 months. Only one patient progressed with fistula reactivation and recurrence of infection. Conclusion: NPWT can be used in wound complications and infection following THA procedures safely and with promising results. Randomized prospective studies should be conducted to confirm its effectiveness. Level of Evidence IV, Case Series.

Keywords: Negative-pressure wound therapy. Arthroplasty, replacement, hip. Surgical wound dehiscence.

\section{RESUMO}

Objetivo: Apresentar a experiência com terapia com pressão negativa (TPN), como adjuvante no tratamento das feridas cirúrgicas de pacientes submetidos à revisão decorrente de solturas sépticas com presença de fístula ativa em artroplastias totais do quadril (ATQ). Métodos: Foram avaliados prospectivamente pacientes que apresentavam infecção de ATQ, associada à presença de fístula, tratados com dispositivo PICO ${ }^{\circledR}$ para TPN, além do tratamento padrão da infecção protética em nossa instituição. Consideramos como desfecho favorável inicial a resolução do processo de infecção e a cicatrização da ferida operatória, sem eventos complicadores. Resultados: Foram acompanhados 10 pacientes que usaram $P I C O^{\circledR}$ em nosso serviço. Não foram identificadas quaisquer complicações com relação ao uso do dispositivo de TPN. A média de acompanhamento dos pacientes após o uso do dispositivo foi de 12,7 meses. Apenas um paciente evoluiu com recidiva da infecção e reativação da fístula. Conclusão: $A$ TPN pode ser usada em complicações de feridas e infecção depois de ATQ com segurança e com resultados promissores. Estudos prospectivos randomizados devem ser realizados para comprovar sua eficácia. Nível de Evidência IV, Série de Casos.

Descritores: Tratamento de ferimentos com pressão negativa. Artroplastia de quadril. Deiscência da ferida operatória.

Citation: Miyahara HS, Serzedello FR, Ejnisman L, Lima ALLM, Vicente JRN, Helito CP. Incisional negative-pressure wound therapy in revision total hip arthroplasty due to infection. Acta Ortop Bras. [online]. 2018;26(5):300-4. Available from URL: http://www.scielo.br/aob.

\section{INTRODUCTION}

Total hip arthroplasty (THA) is the standard of care for cases of primary or secondary osteoarthrosis in which conservative treatment has failed. With the increase in the number of arthroplasties and the number of young and old patients with more comorbidities, the number of revision surgeries and complications of this procedure have also increased, including surgical wound complications and infections. Known risk factors for skin complications and postoperative infection after THA include rheumatological diseases, diabetes, obesity, poor nutrition, smoking, and chiefly, previous surgeries. ${ }^{1}$ Some of the measures recommended in the literature to decrease the risk of infection after THA include the use of prophylactic antibiotics before the incision, shaving with a trichotomizer and not with a blade, adequate sanitazation of the hands and forearms, a strictly sterile technique, preparation of the skin with an alcohol solution, control of comorbidities such as diabetes and malnutrition in the perioperative

Conflicts of interest: Author Camilo Partezani Helito is a speaker for Smith-Nephew. Author José Ricardo Negreiros Vicente is a speaker for Stryker. All other authors declare no potential conflict of interest related to this article.

Work conducted at the Universidade de São Paulo, Faculdade de Medicina, Department of Orthopedics and Traumatology, Laboratório de Investigação Médica do Sistema Musculoesquelético, Hip Surgery Division, São Paulo, SP, Brazil.

Correspondence: Helder de Souza Miyahara. Rua Dr. Ovídio Pires de Campos, 333, Cerqueira Cesar, São Paulo, SP, Brazil. 05403-010. helder_miyahara@hotmail.com 
period, maintenance of normothermia during the procedure, and an adequate surgical technique, accounting for the dissection planes and minimizing the pressure of the skin retractors to avoid skin damage. ${ }^{2}$ Upon the diagnosis of prosthetic infection, treatment varies from antibiotic therapy to surgical cleaning, implant removal, and placement of spacers with antibiotics. Normally, the treatment is lengthy and involves decline of quality of life and function of the patients, and it is associated with high costs to health services. ${ }^{3}$

Negative-pressure wound therapy (NPWT) is a form of adjuvant treatment that has been gaining attention recently in the orthopedic literature. Although its use is well established in other areas of medicine and orthopedics, especially in cases of trauma with severe lesions in soft parts and exposed fractures, ${ }^{4-6}$ its use in the field of primary arthroplasties and prosthetic revision surgeries is still not well established. Studies of cases of periprosthetic fractures after knee and hip and ankle arthroplasties have demonstrated the benefit of using this type of therapy. ${ }^{4,7}$ However, few studies have demonstrated the use of this procedure in cases of primary arthroplasties, and these do not allow a definite conclusion regarding its use. Despite the theoretical benefit reported in a recent review, no prospective studies have clearly documented its benefits. Some of the patients that can benefit from NPWT in hip arthroplasty are those with complications such as dehiscence or prolonged secretion by the surgical wound and those with infection, which would present greater damage to the skin and soft parts that hinder healing.

Thus, the objective of this study was to describe our experience with NPWT in the treatment of surgical wounds in patients who had undergone THA revision by septic loosening in the presence of fistula.

\section{MATERIALS AND METHODS}

Ten cases of THA revision were prospectively evaluated because of septic loosening with active fistula (Figure 1). The study was approved by the ethics committee of the institution under registration of protocol IOT-1117, and informed consent was obtained from the included patients. From the time of hospitalization, patients who had an active fistula and signs of prosthetic release on radiographs in at least one of the components were treated using the following protocol for arthroplasty infection at our institution: two-time revision surgery, which involves antibiotic therapy associated with surgical cleaning and debridement with removal of the implant and placement of a cement spacer with antibiotic (femoral and acetabular; Figure 2) and subsequent replacement of implants, using the surgical technique as needed in each case. In some cases, homologous bone grafts

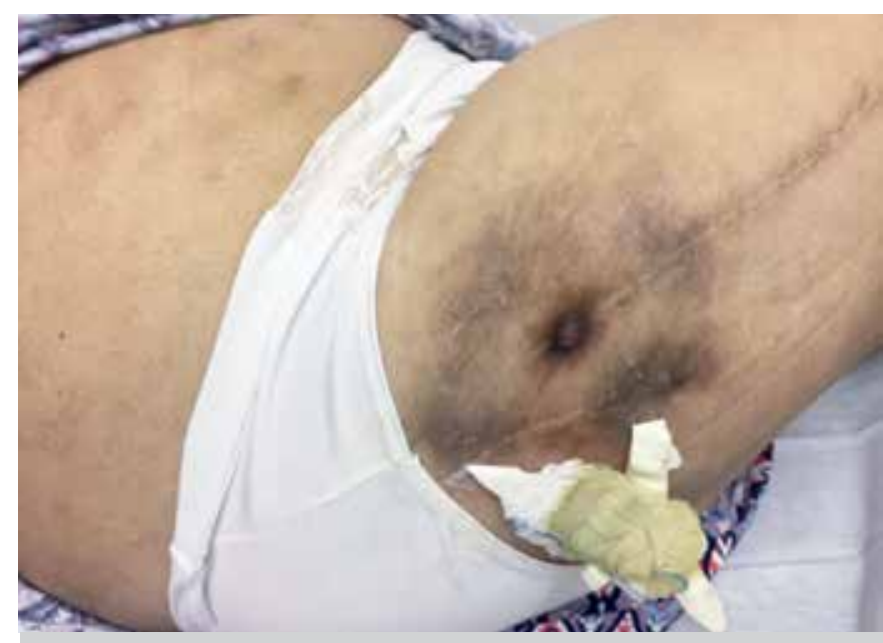

Figure 1. A patient with septic loosening after total hip arthroplasty, featuring an active fistula. were used for acetabular bone defects associated with a reinforcement ring; in others, non-cemented metal cups were used. In the femoral part, the cases were resolved with cementless primary or modular stems for distal fixation or impacted graft technique with short cemented stems. After the usual treatment, at the time of the implant replacement and during the second treatment, the NPWT device was placed on the wound as an additional measure (Figure 3). Intraoperative culture samples were harvested during all surgeries, and postoperative antibiotic therapy was defined in accordance with the antibiogram.

The use of the device did not prevent the patients from receiving the standard rehabilitation that would be used in the case of nonuse of the device. Thus, the amplitude of movement and gait with partial load were encouraged, except when contraindicated for the surgical procedure. The portable device PICO $10 \times 40$ (Smith \& Nephew) was used in this study, with a continuous negative pressure of 80 $\mathrm{mmHg}$. After 7 days, the duration of operation using the device, the wound, and appearance of the dressing (Figure 4) were analyzed, and the need to install a new device was determined. This procedure was performed every 7 days, when the appliance was shut down. The total time of therapy for each patient was quantified.

The resolution of the infection process, closure of the fistula, andgood evolution of the surgical wound (Figure 5), without complicating events or the need for a new surgical intervention, were considered initial favorable outcomes.

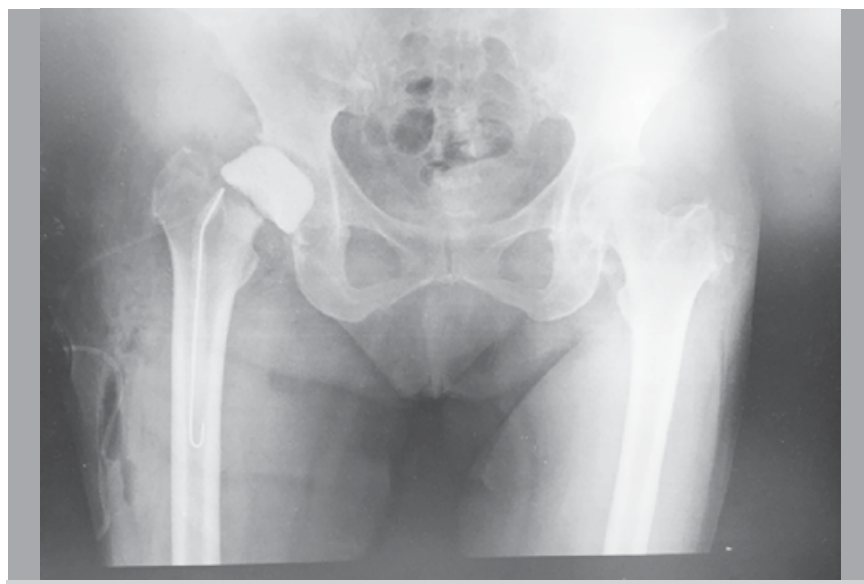

Figure 2. Anteroposterior radiograph of the pelvis demonstrating use of a spacer with antibiotics.

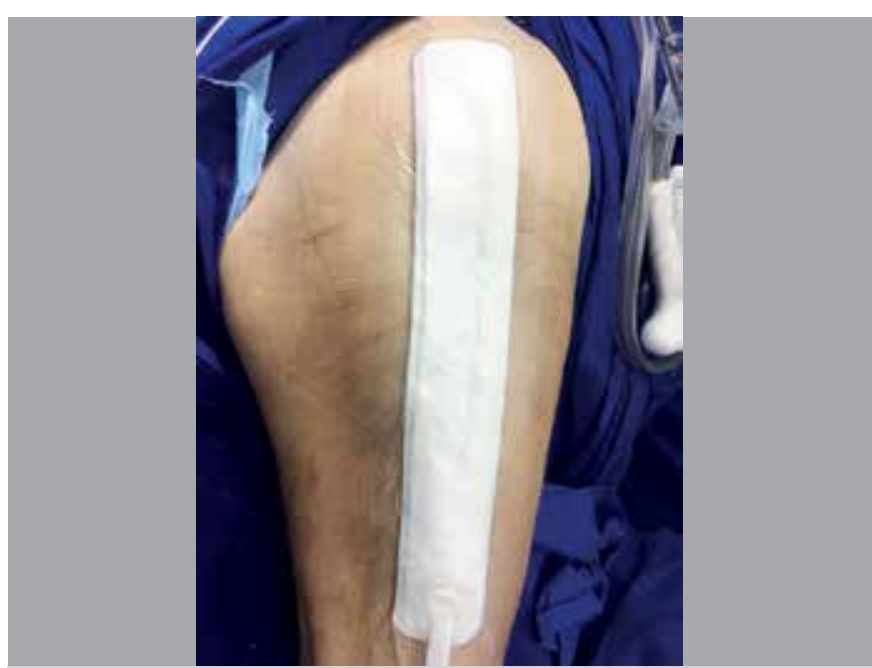

Figure 3. Negative-pressure therapy device applied over the wound. 

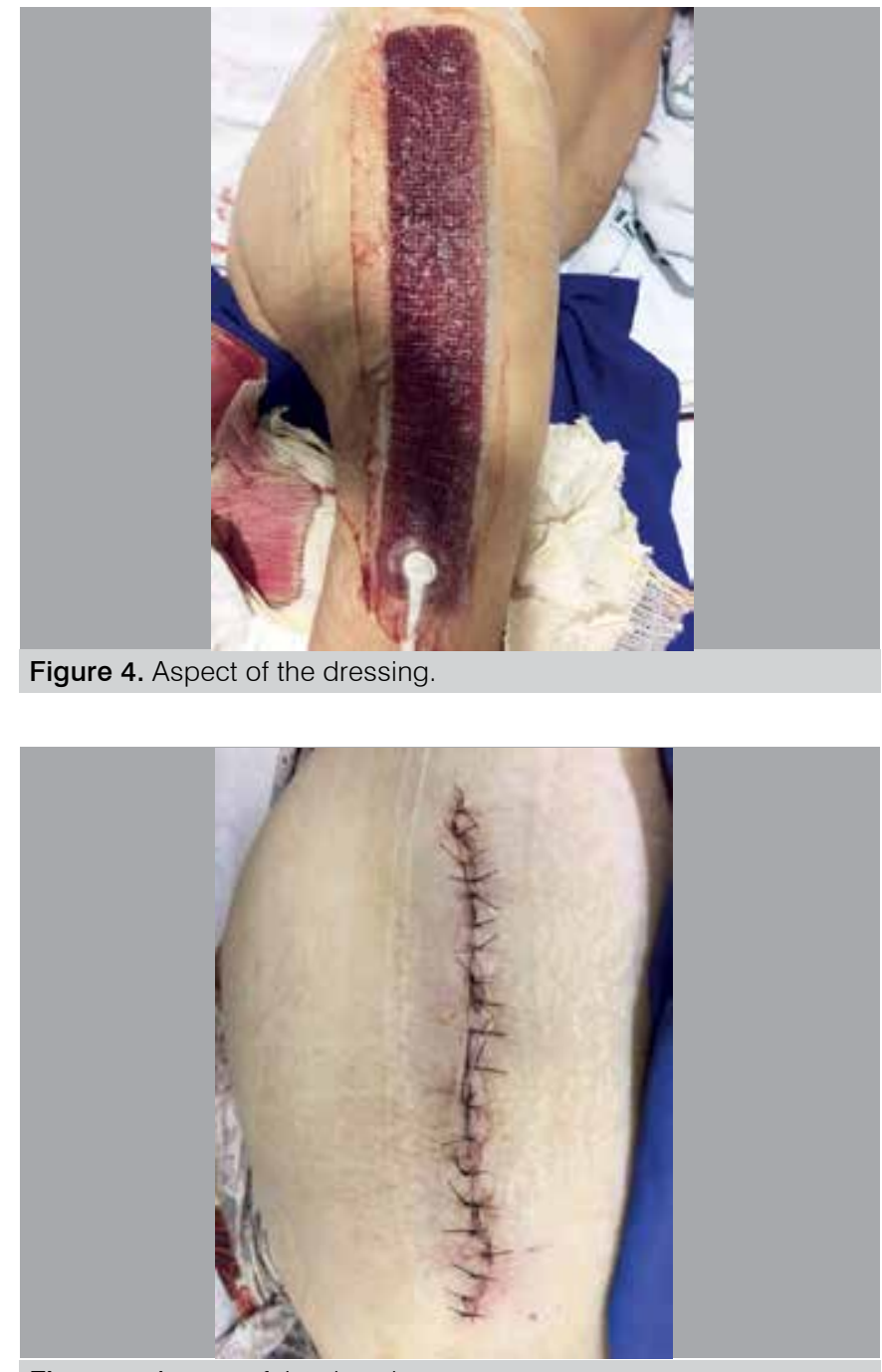

Figure 4. Aspect of the dressing.

\section{RESULTS}

Ten patients diagnosed as having septic loosening with an active fistula underwent a two-stage THA revision, and PICO was used in the second revision when the implants were placed. The patients' data are summarized in Table 1. Four patients had rheumatoid arthritis and four others were smokers. Two patients used the device for 21 days (three sets of dressings), one with rheumatoid arthritis and the other a smoker. Eight patients used it for 7 days (one set). The average use for each patient was 9.8 days. None of the patients required therapy for more than 3 weeks.

In relation to the outcome, nine patients presented with a favorable outcome based on the established criteria as follows: one patient had reactivation of the fistula 1 year after the operation (after the implants were replaced) and when a surgical reapproach was needed; the other nine patients presented with wound closure and control of the infectious processes without the need for reintervention until the end of follow-up.

No complications were associated with the use of NPWT. The mean follow-up of the patients after the use of the device was 12.7 months, ranging from 12 to 16 months.

\section{DISCUSSION}

The main finding of this study was that NPWT may be safely used in revision surgeries of hip prosthesis for chronic infection, without

\begin{tabular}{c|c|c|c|c|c|c|c}
\hline \multicolumn{2}{l}{ Table 1. Patients' data. } \\
\hline Patient & Age & Sex & Comorbidities & $\begin{array}{c}\text { Days } \\
\text { of use }\end{array}$ & $\begin{array}{c}\text { No. Of } \\
\text { dressings }\end{array}$ & $\begin{array}{c}\text { Follow-up } \\
\text { (months) }\end{array}$ & Resolution \\
\hline 1 & 46 & Female & $\begin{array}{c}\text { Rheumatoid } \\
\text { Arthritis }\end{array}$ & 21 & 3 & 15 & Yes \\
\hline 2 & 46 & Female & $\begin{array}{c}\text { Rheumatoid } \\
\text { Arthritis }\end{array}$ & 7 & 1 & 12 & Yes \\
\hline 3 & 65 & Male & Smoker & 7 & 1 & 16 & No \\
\hline 4 & 65 & Male & Smoker & 7 & 1 & 12 & Yes \\
\hline 5 & 65 & Male & Smoker & 21 & 3 & 12 & Yes \\
\hline 6 & 65 & Male & Smoker & 7 & 1 & 12 & Yes \\
\hline 7 & 78 & Female & $\begin{array}{c}\text { Rheumatoid } \\
\text { Arthritis }\end{array}$ & 7 & 1 & 12 & Yes \\
\hline 8 & 78 & Female & $\begin{array}{c}\text { Rheumatoid } \\
\text { Arthritis }\end{array}$ & 7 & 1 & 12 & Yes \\
\hline 9 & 85 & Female & $\begin{array}{c}\text { Obesity/ } \\
\text { SAH/DM }\end{array}$ & 7 & 1 & 12 & Yes \\
\hline 10 & 32 & Male & $\begin{array}{c}\text { Sickle Cell } \\
\text { Anemia }\end{array}$ & 7 & 1 & 12 & Yes \\
\hline
\end{tabular}

SAH: systemic arterial hypertension; DM: diabetes mellitus.

any complications and impairment of the rehabilitation of patients, and with satisfactory initial results.

Among the described mechanisms of action of NPWT, which are potentially important in its use in arthroplasties, are the removal of fluid; decrease in edema, dead space, and soluble inflammatory molecules; mechanical stabilization; reduction of tension on the wound; and increased blood flow and angiogenesis. ${ }^{8}$ DeCarbo et al. conducted a study involving NPWT in hindfoot and ankle lesions and wounds, and demonstrated improvement in edema, pain control, and healing. ${ }^{9}$

The usefulness of NPWT has not been proven in arthroplasty surgeries, although several authors have shown a potential benefit of its use as an adjuvant therapy. A recent study by Strugala et al. showed a shorter hospitalization duration and lower incidence rates of dehiscence and postoperative infections with the use of the PICO dressing. ${ }^{10}$ In a study that used primary total hip prosthesis, Gillespie et al. observed a reduction of $3 \%$ in the number of infections with the use of NPWT and recommend a series with approximately 900 patients to achieve a statistically significant result regarding the incidence of infectious complications related to the procedure. ${ }^{11}$ Karlakki et al. reported a shorter hospitalization time with the use of negative pressure dressings in primary prosthesis of the knee and hip than with the use of conventional dressings. ${ }^{12}$ Pachowsky et al. concluded an improvement in the drainage of persistent seroma and, consequently, better healing in THA cases. ${ }^{13}$ Cooper showed a lower number of infections and no relevant complication with the use of NPWT in revision surgeries of hip and knee prostheses. ${ }^{15}$ Ene et al. conducted a study with infected knee prosthesis and obtained good results (no wound dehiscence and complications) with the use of NPWT.16 In a series of 10 cases of complex lesions of the knee, Helito et al. demonstrated promising results in the healing of wounds and no complications with the use of NPWT. ${ }^{17}$

Nonetheless, a randomized study that involved the use of NPWT in knee arthroplasties had to be terminated before its completion because of the formation of blisters around the skin lesion. To prevent blister formation, technological changes have already been incorporated in new devices, which minimized this problem. We did not find this type of complication in our series. The NPWT system used (PICO) consisted of a silicone dressing in multiple layers, designed to prevent blister formation or maceration of the wound..$^{18}$ In our series, 
no other complications occurred that were directly related to the use of NPWT, similar to other studies that used the same updated device. In our study, the patient with recurrence of fistula had rheumatoid arthritis as a comorbidity. Sun et al. already reported worse results in patients with rheumatoid arthritis. ${ }^{19}$

Contrary to the studies that showed benefits, other authors such as Manoharan et al. observed no clinical benefit or cost reduction with the use of negative-pressure dressings. ${ }^{20}$

Although we did not find complications in this series, NPWT should be used with caution. Situations such as the exposure of neurovascular bundles or unexplored fistulas are contraindications to the use of NPWT. Patients with coagulopathies or those taking anticoagulants should be monitored with caution when using the device. Circumferential dressings should also be avoided to prevent possible limb ischemia

Another important benefit of the type of therapy used in this study is the possibility of outpatient treatment. Once the bandage is placed, the patient needs to perform daily changes, and the device can be carried with ease. Payne et al. studied the use of these devices for the most diverse types of skin infections and lesions and showed a possible reduction of costs due to no hospitalization required. ${ }^{21}$
Frazão et al. reported a significant increase in costs for the treatment of hip arthroplasty infections in a tertiary hospital as compared with cases without infection. ${ }^{3}$ Thus, any economy with safety for the patient may be important for the health system.

Despite the small number of cases, the initial results presented in this study are promising. In the treatment of infections, NPWT can be used as an adjunct procedure for the treatment of patients, in no way replacing the treatment algorithm and the consecrated conduct of antibiotic therapy, surgical cleaning, and implant removal. The small number of patients and the short follow-up time, in addition to the heterogeneous sample and absence of a control group are the limitations of this study. Nevertheless, we believe that the study obtained satisfactory results and the results are beneficial as they demonstrate the absence of possible complications and reinforce indications for the use of NPWT.

\section{CONCLUSION}

NPWT may be safely used in surgical revision of hip prosthesis due to septic loosening, with promising results. Long-term prospective randomized studies with larger samples should be conducted to prove their effectiveness.

AUTHORS' CONTRIBUTIONS: Each author contributed individually and significantly to the development of this work. HSM (0000-0002-2532-2685)* was responsible for the design of the study, bibliographic survey, participation in surgical procedures, and supervision. FRS (0000-0001-8430-536X)* participated in the bibliographic survey, and data acquisition and analysis. LE (0000-0002-9866-1960)* participated in the surgical procedures, data interpretation, and drafting of the manuscript. ALLML (0000-0002-2396-9880)* and JRNV (0000-0003-3528-9249)* guided, critically analyzed, reviewed, and oversaw all phases of the work. CPH (0000-0003-1139-2524)* participated in the intellectual conceptualization, surgical procedures, and drafting of the manuscript. ${ }^{\star} \mathrm{ORCID}$ (Open Researcher and Contributor ID).

\section{REFERENCES}

1. wito A, Wodka-Natkaniec E, Nied wiedzki , Ga dzik T, Nied wiedzki T Activity and Quality of Life after Total Hip Arthroplasty. Ortop Traumatol Rehabil. 2017;19(5):441-50.

2. Almustafa MA, Ewen AM, Deakin AH, Picard F, Clarke JV, Mahmood FF. Risk Factors for Surgical Site Infection Following Lower Limb Arthroplasty: A Retrospective Cohort Analysis of 3932 Lower Limb Arthroplasty Procedures in a High Volume Arthroplasty Unit. J Arthroplasty. 2018;33(6):1861-7.

3. Frazão VL, Miyahara HS, Kirihara RA, Lima ALLM, Croci AT, Vicente JRN. Social profile and cost analysis of deep infection following total hip replacement surgery. Rev Bras Ortop. 2017;52(6):720-724.

4. Cooper HJ, Roc GC, Bas MA, Berliner ZP, Hepinstall MS, Rodriguez JA, et al. Closed incision negative pressure therapy decreases complications after periprosthetic fracture surgery around the hip and knee. Injury. 2018;49(2):386-91.

5. Brem MH, Bail HJ, Biber R. Value of incisional negative pressure wound therapy in orthopaedic surgery. Int Wound J. 2014;11 Suppl 1:3-5.

6. Kelm J, Schmitt E, Anagnostakos K. Vacuum-assisted closure in the treatment of early hip joint infections. Int J Med Sci. 2009;6(5):241-6.

7. Matsumoto T, Parekh SG. Use of Negative Pressure Wound Therapy on Closed Surgical Incision After Total Ankle Arthroplasty. Foot Ankle Int. 2015;36(7):787-94.

8. Siqueira MB, Ramanathan D, Klika AK, Higuera CA, Barsoum WK. Role of negative pressure wound therapy in total hip and knee arthroplasty. World $\mathrm{J}$ Orthop. 2016;7(1):30-7.

9. DeCarbo WT, Hyer CF. Negative-pressure wound therapy applied to high-risk surgical incisions. J Foot Ankle Surg. 2010;49(3):299-300.

10. Strugala V, Martin R. Meta-Analysis of Comparative Trials Evaluating a Prophylactic Single-Use Negative Pressure Wound Therapy System for the Prevention of Surgical Site Complications. Surg Infect (Larchmt). 2017;18(7):810-9.

11. Gillespie BM, Rickard CM, Thalib L, Kang E, Finigan T, Homer A, et al. Use of Negative-Pressure Wound Dressings to Prevent Surgical Site Complications After Primary Hip Arthroplasty: A Pilot RCT. Surg Innov. 2015;22(5):488-95.
12. Karlakki SL, Hamad AK, Whittall C, Graham NM, Banerjee RD, Kuiper JH. Incisional negative pressure wound therapy dressings (iNPWTd) in routine primary hip and knee arthroplasties: A randomised controlled trial. Bone Joint Res. 2016;5(8):328-37.

13. Pachowsky M, Gusinde J, Klein A, Lehrl S, Schulz-Drost S, Schlechtweg P Pauser J, Gelse K, Brem MH. Negative pressure wound therapy to prevent seromas and treat surgical incisions after total hip arthroplasty. Int Orthop. 2012;36(4):719-22.

14. Cooper HJ, Bas MA. Closed-Incision Negative-Pressure Therapy Versus Antimicrobial Dressings After Revision Hip and Knee Surgery: A Comparative Study. J Arthroplasty. 2016;31(5):1047-52.

15. Ene R, Panti Z, Albu E, Ene P, Cirstoiu MM, Cirstoiu FC. Negative Pressure, a "Solution" in the Treatment of Infected Knee Prosthesis? Maedica (Buchar) 2015;10(1):5-9.

16. Helito CP, Bueno DK, Giglio PN, Bonadio MB, Pécora JR, Demange MK. Negative- Pressure wound therapy in the treatment of complex injuries after total knee arthroplasty. Acta Ortop Bras. 2017;25(2):85-8.

17. Hudson DA, Adams KG, Van Huyssteen A, Martin R, Huddleston EM. Simplified negative pressure wound therapy: clinical evaluation of an ultraportable, no-canister system. Int Wound J. 2015;12(2):195-201.

18. Sun Z, Sun Y, Cao J, Wang L, Tian M, Zhang Y, et al. [Cause analysis and clinical management of postoperative wound complications after total knee arthroplasty]. Zhongguo Xiu Fu Chong Jian Wai Ke Za Zhi. 2009;23(6):644-7.

19. Manoharan V, Grant AL, Harris AC, Hazratwala K, Wilkinson MP, McEwen PJ. Closed Incision Negative Pressure Wound Therapy vs Conventional Dry Dressings After Primary Knee Arthroplasty: A Randomized Controlled Study. J Arthroplasty. 2016;31(11):2487-94.

20. Payne C, Edwards D. Application of the Single Use Negative Pressure Wound Therapy Device (PICO) on a Heterogeneous Group of Surgical and Traumatic Wounds. Eplasty. 2014;14:e20. 
Appendix 1. Mapping of the injuries sustained in the 2017 São Paulo state football championship.

\begin{tabular}{|c|c|}
\hline Report on orthopedic injuries \\
(19.j) \\
$\begin{array}{c}\text { Rustained during the } 2017 \text { São Paulo } \\
\text { state football championship }\end{array}$ \\
\hline
\end{tabular}

1. This report refers to the following match:
2. What was the weather like at the time of the match?
$\square$ Sunny
$\square$ Cloudy
$\square$ Rainy
$\square$ Sun shower
$\square \quad$ Rain and lightning
$\square$ Night - clear sky
$\square$ Night - rainy

3. Temperature measured at the time of the match:
4. Location
$\square$ Home game
$\square \quad$ Up to $200 \mathrm{~km}$ away
$\square$ From 200 to $400 \mathrm{~km}$ away
$\square$ More than $400 \mathrm{~km}$ away
5. Were there injuries sustained during the match?
$\square$ Yes
$\square \quad$ No

Fill out the following items only if injuries were sustained 6. Name of the injured athlete:

Date of birth:
7. Athlete's position:
$\square$ Goalkeeper
$\square$ Central defender
$\square$ External defender
$\square$ External midfielder
$\square$ Central midfielder
$\square$ Forward
8. When was the injury sustained?
$\square \quad 0-15 \mathrm{Min}$
$\square \quad$ 15-30 Min
$\square \quad 30-45 \mathrm{Min}$
$\square \quad$ 45-60 Min
$\square \quad 60-75 \mathrm{Min}$
$\square \quad$ 75-90 Min
$\square$ Overtime $-1^{\text {st }}$ half
$\square$ Overtime $-2^{\text {nd }}$ half

9. Did the injury occur after contact or collision with the ball, goal or with another athlete?

$\square$ Yes

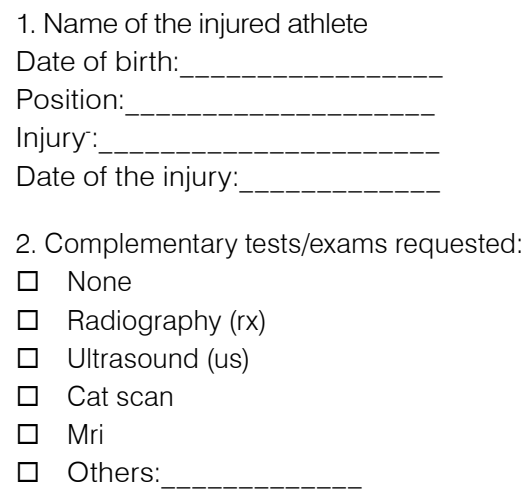

3. Did the injury require surgery?

$\square$ Yes

$\square \quad$ No

4. If yes, specify:

5. Athlete's return date to sports activities:

6. Days of time loss:

7) Injury severity scale:

$\square$ Slight (up to 3 days of time loss)

$\square \quad$ Minor (3 to 7 days of time loss)

$\square \quad$ Mild (7 to 28 days of time loss)

$\square \quad$ Major (7 days to 8 weeks of time loss)

$\square$ Severe (more than 8 weeks of time loss)

8) Did the final diagnosis confirm the initial diagnosis?

$\square$ Yes

$\square \quad$ No

Final diagnosis: 